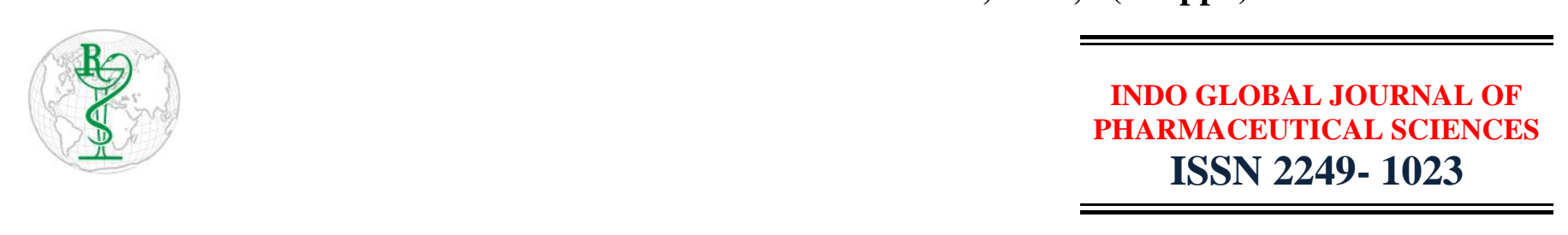

\title{
Role of Metallic Nanoparticles in the Treatment of Diabetes Mellitus
}

\author{
Yogita Kumari*, Gurmandeep Kaur, Clarisse Ayinkamiye, Sachin Kumar Singh, Rajesh Kumar, \\ Rubiya Khursheed
}

School of Pharmaceutical Sciences, Lovely Professional University, Phagwara-144411, Punjab, India

Address for Correspondence: Yogita Kumari; kyogita72@gmail.com

\begin{abstract}
Received:
01.03.2019

Accepted:

25.03.2019

Keywords

Metallic

Nanoparticles;

Diabetes; Insulin;

Oral Delivery.
\end{abstract}

\begin{abstract}
Diabetes mellitus (DM) is a well-known threat to mankind for more than 2000 years. DM is a group of metabolic disorder characterized by a complete lack of insulin, a relative lack of insulin, or insulin resistance. The prevalence of diabetes is rapidly rising all over the globe at an alarming rate and as per international diabetes federation (IDF); diabetes is expected to become the seventh largest cause of death worldwide by 2030. Treatment of diabetes need constant monitoring of blood glucose level, regulating it through modified dietary sugar intake and insulin therapy. Current dosage of injectable insulin comprises of up to two- three subcutaneous injections per day which can cause psychological stress leading to poor patient compliance. At present several researchers have been focusing on new management options for diabetes. Among these options the use of metallic nanoparticles is becoming an eye catching and most promising due to their non-invasiveness and site specificity. Metallic nanoparticles hold substantial potential for improving the care of patients with diabetes as it allows oral delivery of insulin to the specific site thus increasing its bioavailability and pharmacological efficacies. The current presentation focuses on oral delivery of insulin using metallic nanoparticles. (C) 2019 iGlobal Research and Publishing Foundation. All rights reserved.
\end{abstract}

Cite this article as: Kumari, Y.; Kaur, G.; Ayinkamiye, C.; Singh, S.K.; Kumar, R.; Khursheed, R. Role of Metallic Nanoparticles in the Treatment of Diabetes Mellitus. Indo Global J. Pharm. Sci., 2019; 9(2Suppl.): 121. DOI: http://doi.org/10.35652/IGJPS.2019.92S19.

Indo Global Journal of Pharmaceutical Sciences( ISSN 2249 1023; CODEN- IGJPAI; NLM ID: 101610675) indexed and abstracted in CrossRef (DOI Enabling), UGC CARE Journal List, EMBASE(Elsevier), National Library of Medicine (NLM) Catalog, ResearchGate, Publons, CAS (ACS), Index Copernicus, Google Scholar and many more. For further details, visit http://iglobaljournal.com

This is a special issue as an outcome of 'RAPSCON-2019' sponsored by APTI and organized by Sri Sai College of Pharmacy, Manawala, Amritsar, Punjab, India. Relaxation offered in journal format. 